\title{
Constelaciones metafóricas de la memoria: Sumar de Diamela Eltit*
}

\author{
Metaphorical constellations of memory: \\ Sumar by Diamela Eltit
}

Mario Federico David Cabrera**

\section{RESUMEN}

En este artículo me propongo analizar la novela Sumar (2018) de Palabras clave: Diamela Eltit a partir de la configuración discursiva de tres tópiDiamela Eltit, cos que funcionan como metáforas asociadas a la problemática memoria, de la memoria: el cuerpo de la narradora, el desplazamiento de posdictadura. los ambulantes hacia La Moneda y la idea de nube/archivo. Sostengo, a modo de hipótesis, que la noción de memoria se presenta en esta novela como un punto de exploración estética y como una preocupación política central para pensar el presente.

\begin{abstract}
In this article, I analyze the novel Sumar (2018) by Diamela Eltit from the discursive configuration of three topics that function as metaphors associated with the problem of memory: the body of the narrator, the worker's march to La Moneda, and the idea of cloud/archive. I consider, as an hypothesis, that the notion of memory is presented in this novel as a point of aesthetic exploration and a key political concern for analyzing the present day.
\end{abstract} Keywords: Diamela Eltit, memory, postdictatorship

El presente artículo se desprende de una línea investigativa del autor y del trabajo realizado en el marco de la tesis de doctorado "La narrativa de Diamela Eltit (1983-2018): metaficción, metáforas del cuerpo y cartografías marginales", en curso.

** Argentino. Magíster en Estudios Latinoamericanos. Profesor Asociado en la Universidad Nacional de San Juan y becario doctoral de CONICET, San Juan, Argentina. federicodavidcabrera@gmail.com 


\section{Repasando imágenes}

Aunque sorteamos el permanente bombardeo a La Moneda, no logramos evadirla

Diamela Eltit, Sumar

A principios de la década del 2000, en el ensayo "Sociedad anónima" Diamela Eltit ${ }^{1}$ se pregunta qué imágenes nos ha dejado el siglo XX chileno. Si bien la respuesta incluye un amplio derrotero de detalles crueles (el desgarro de los derechos ciudadanos, la exclusión de grandes franjas de la sociedad, la tortura y desaparición de los cuerpos, entre otros), la autora considera que la representación del siglo se organiza (o, mejor dicho, ha quedado presa) en torno al golpe de Estado del 11 de septiembre de 1973 como "una ordenación circular que permitirá atisbar, con una cierta nitidez, la escalada programática de los distintos hechos de violencia que han recorrido los últimos cien años" (Eltit, Sociedad anónima 29).

En efecto, la llegada al poder de Augusto Pinochet no solo implicó una reestructuración del Estado de acuerdo con los diseños geopolíticos del neoliberalismo, sino sobre todo, el despliegue de una tecnología de control, subordinación y aniquilación de las resistencias. Por un lado, en el orden de lo económico, Chile se constituyó como el laboratorio de las recetas económicas de la escuela de Chicago o la llamada economía del "shock". El país lleva a cabo profundas transformaciones en la estructura social y en la forma de ejercer el poder: la actividad industrial queda subsumida a otras prácticas entre las que adquiere mayor preponderancia la especulación financiera; la banca nacional

Diamela Eltit (Santiago, 1949) es Licenciada en Letras por la Universidad de Chile. Ha ejercido como docente de la Universidad Tecnológica Metropolitana y como profesora invitada en las universidades de Cambridge, Columbia, Berkeley, Stanford, Washington y Johns Hopkins, entre otras. En el campo artístico, fue una de las fundadoras del Colectivo de Acciones de Arte (CADA) a fines de los 70, movimiento que tendió a reformular y rearticular las relaciones público/obra y arte/política en el marco de la censura y el terror de la dictadura. Ha publicado tres libros que recopilan ensayos y artículos de su autoría: Emergencias (2000), Signos vitales (2008) y Réplicas (2016). Su obra narrativa comprende las novelas Lumpérica (1983), Por la patria (1986), El cuarto mundo (1988), Vaca sagrada (1991), Los vigilantes (1994), Los trabajadores de la muerte (1998), Mano de obra (2002), Jamás el fuego nunca (2007), Impuesto a la carne (2010), Fuerzas especiales (2013) y Sumar (2018), además de las narraciones testimoniales El padre mío (1989) y Puño y letra (2005). 
sufre una fuerte extranjerización; se disminuye notablemente la clase obrera a la vez que la negociación colectiva se reduce al sindicato de empresa; la economía agraria capitalista y empresarial se amplía en detrimento del número de asalariados agrícolas. El Estado queda así reducido a su mínima expresión como garante del respeto de la propiedad privada y de los intereses empresariales (Faletto 75). Esto se ve acompañado del aumento del desempleo, la disminución del poder adquisitivo de los trabajadores, la privatización de empresas estatales y de una reducción brutal del presupuesto para hospitales públicos, y, por supuesto, para la educación.

Por otra parte, en lo que se refiere a la represión y al terrorismo de Estado, la dictadura inicia un proceso de persecución, encarcelamiento y ejecución de los enemigos políticos del régimen. Se instaura como política el estado de sitio, el toque de queda y la persecución de representantes de la Unidad Popular². Además, se prohíbe la actividad sindical y se intervienen los órganos de prensa y las universidades. El terrorismo de Estado se presenta como una estrategia de socialización del miedo a través de la tensión indefinida y voluntariamente sostenida entre el orden del secreto y el de lo velado. Es decir que, a pesar de la clandestinidad de las operaciones, la narrativa del miedo se construye como un secreto a voces que impone en la ciudadanía la necesidad del cuidado frente a la mirada del poder (Rotger 42). Esta operatoria genera un doble desgarramiento en el plano de lo simbólico: manifiesta un marcado interés por divorciar los lenguajes de las historias oficiales respecto de la experiencia y las voces de la doxa, por un lado, y obstaculiza cualquier intento de reconstruir una memoria de lo acontecido, por otro. Nelly Richard, en diálogo con Benjamin, esboza un diagnóstico de esta situación:

La falta de sepultura es la imagen — sin cubrir — del duelo histórico que no termina de asimilar el sentido de la pérdida y que mantiene ese sentido en una versión inacabada, transicional. Pero es también

La Dirección Nacional de Inteligencia (DINA) y, luego, el Centro Nacional de Informaciones (CIN) se encargaron de llevar a cabo la persecución y tortura de los distintos frentes opositores. Además, entre 1974 y 1978 operan junto con las organizaciones de inteligencia de Estados Unidos, Brasil, Argentina, Uruguay y Paraguay en la Operación Cóndor, plan supraestatal de represión que llevó a cabo el secuestro, entrega y asesinato extrajudicial de exiliados entre los Estados que participaban. 
la condición metafórica de una temporalidad no sellada: inconclusa, abierta entonces a ser reexplorada en muchas nuevas direcciones por una memoria nuestra cada vez más activa y disconforme. (Richard, La insubordinación... 13)

En la década del 90, pese al cambio en el ejercicio institucional del poder del Estado, los gobiernos de la transición establecen un pacto entre redemocratización y neoliberalismo que deja fuera de escena la problemática de la memoria, el duelo y las demandas de sectores excluidos (Ansaldi y Giordano 552; Brunner 53; Dorfman 190). Esto ha dado lugar a un autoritarismo de mercado que determina gran parte de la estructuración social de Chile aún en el presente. Pensemos, por ejemplo, en la histórica demanda de los jóvenes chilenos por la gratuidad de la educación superior, en la llegada a la presidencia de una figura empresarial como la de Sebastián Piñera y en las reivindicaciones de Pinochet que han realizado muchos de sus seguidores.

En este contexto, la figura de Diamela Eltit desarrolla una trayectoria estética y política que interviene de manera crítica respecto de la conformación de un discurso social atravesado por el autoritarismo, la impunidad, el olvido y la naturalización de la desigualdad social. A través de la performance, las instalaciones callejeras y el videoarte a fines de la década del 70 y comienzos de los 80 , las prácticas artísticas de la autora insisten en repensar las relaciones entre estética y política, desafiar las "morales del sentido único regidas por un binarismo simple de negación/afirmación” (Richard, Feminismo... 90) y orientar la mirada hacia sujetos e identificaciones marginales ${ }^{3}$. En 1983, la aparición de Lumpérica, su primera novela, marca un hito en la construcción de una narrativa posterior al golpe de Estado (Richard Tres funciones... 38; Cánovas 25) y demarca una forma de trabajo que se complejiza a lo largo de toda su producción literaria: una experimentación múltiple que impugna la noción naturalista de

\footnotetext{
Al respecto, Rubí Carreño Bolívar sostiene que el proyecto narrativo de Eltit “[...] vulnera varias de las tradiciones hegemónicas chilenas, como por ejemplo, el imperio de la literatura realista en colusión con el fundo mental como orden social; la construcción de un sujeto popular que se escapa de las retóricas de la caridad o de la seguridad ciudadana y que en vez de hablar de redimido tras las rejas, cuenta la historia, aunque sea a través de las huellas que dejan en su cuerpo el vino, la tortura o la automutilación. A esto, se suma en su narrativa reciente, la crítica a la omnipresencia del mercado que destruye colectivos que van desde la familia y el gremio hasta la nación" (145).
} 
representación, hace uso de metáforas que socavan los dispositivos de control y demanda una participación activa de los lectores en la decodificación de los sentidos ${ }^{4}$. Asimismo, el cuerpo se manifiesta como un mapa (o documento) que permite explorar las huellas de la historia y el autoritarismo (Corbin 2-3) .

Atendiendo a lo señalado, en este artículo me propongo realizar una lectura de la novela Sumar (2018) a partir del análisis de tres tópicos que, desde mi punto de vista, funcionan como metáforas asociadas a la problemática de la memoria: el cuerpo de la narradora, el desplazamiento de los ambulantes hacia La Moneda y la idea de nube/ archivo. En lo que se refiere al encuadre teórico, me sitúo desde una perspectiva intersticial que busca articular saberes de los estudios de la memoria social ${ }^{6} \mathrm{y}$ atender a la especificidad de los discursos literarios. Esto implica, entre muchas otras tareas, intentar responder a la pregunta acerca de la dimensión ética y política del recuerdo en tanto práctica que asigna roles y configura sentidos de amplia resonancia en

"La ruptura del código lingüístico tiene también una equivalencia con la rotura de la piel. Mediante esta rotura última, el cuerpo del texto expresa su deseo de liberación de modelos opresores; el deseo de autogestarse desde una programación distinta, única y nueva, frente a las diferentes prisiones ofrecidas por el sistema oficial" (Brito 112).

"Eltit's texts throughout her career have required this recognition of the corporal. In her first novel, Lumpérica, Eltit forces the reader to face the bloody cuts on her page in order to enter the chaotic existence of Chilean citizen living under dictatorship. This move toward the abject corporality of the sliced and wounded body has remained consistent throughout the trajectory of Eltit's work, with her 1991 novel, Vaca sagrada, exploring the tortured body though the incorporation of expressions of body dysmorphia and marked examination of sadomasochistic relationships. Later, El infarto del alma's denunciation of the Chilean mental health care system occurred via the photographic (re)presentation of the bodies of one facility's patients, drawing the reader to a consideration of the corporal evidence that betrays a differently normal interior psychic state. In her latest novel, Impuesto a la carne, Eltit transports the reader into the bloodied and sickened existence of a mother and daughter suffering through multiplying maladies within the confines of an authoritarian hospital that repeatedly violates the sanctity of the body and the autonomy of the individual. All of these texts reveal a constant within the trajectory of Diamela Eltit's contributions to New Chilean Fiction: the turn to the body's revelatory capacity as a corporal archive of human existence" (Corbin 2-3).

${ }_{6}$ Utilizo la denominación "memoria social" en clara referencia a Halwachs (45) quien entiende la memoria como una práctica social de carácter dinámico y colectivo que produce experiencias del pasado. En lo que se refiere a la memoria social como un campo de estudios, es importante destacar que en el contexto latinoamericano posterior a la década del 80, adquieren especial protagonismo en relación con los procesos de reconstitución democrática y la búsqueda de respuestas ante el horror del terrorismo de estado. Son muchos los trabajos producidos en este campo; en la elaboración de este artículo me han resultado especialmente significativos los aportes de Idelber Avelar (10), Nelly Richard (Latencias... 9-12) y Steve Stern (30). 
el presente. Desde este punto de vista, conceptualizo los discursos literarios y artísticos como piezas fundamentales para la construcción de narrativas memorialistas que exploran las fisuras y tensiones de los discursos oficiales y las experiencias silenciadas (Cabrera 66). Así, sostengo, a modo de hipótesis, que la noción de memoria se presenta en esta novela como un punto de exploración estética y como una preocupación política central para pensar el presente. Parafraseando a Benjamin (67), la memoria relampaguea en las metáforas de Eltit como recuerdo de la precariedad del ahora.

\section{Una frenética máquina de sueños}

Como en un juego de pliegues barrocos, Sumar se construye por la duplicación de las historias que busca representar y en la ambigüedad de sus referentes. La novela cuenta algunos episodios de la gran marcha de los trabajadores y desposeídos que buscan recorrer más doce mil quinientos kilómetros en un lapso de trescientos setenta días ${ }^{7}$ para alcanzar "la moneda". Esto activa un doble régimen de significación: la moneda alude al emplazamiento del poder político, el Palacio de La Moneda, y, a su vez, remite al capital, unidad que regula el consumo (y la vida) en la sociedad neoliberal:

La novela parte de una ambigüedad. La Moneda, como cuerpo arquitectónico ubicable en la historia política de Chile, pero también la moneda como figura económica que concreta la impronta de los tiempos del capital. En este sentido, Eltit responde a la ambigüedad que ha caracterizado la política chilena. El hecho de que el palacio presidencial haya sido ubicado en la Casa de la Moneda abre una imagen que precede y, por qué no, anuncia la instauración de la equivalencia entre economía y política. (Guerrero s/p)

La narración elide cualquier referencia respecto del origen de la marcha y se limita a presentar algunas elucubraciones acerca de lo que sucederá cuando llegué a su fin, cuando los caminantes alcancen la

De acuerdo con Laura Scarabelli, la figura de la marcha parece aludir a una de las más grandes hazañas del partido comunista chino: la Larga Marcha que emprendieron las tropas del Ejército rojo huyendo del Ejército de la República de China entre 1934 y 1935. En coincidencia con la novela, esta gesta implicó el desplazamiento de miles de soldados a los largo de doce mil quinientos kilómetros en trescientos setenta días (Scarabelli 199). 
moneda. Es decir que la escena de enunciación se sitúa in media res, en un momento indefinido de la marcha en la columna de los trabajadores ambulantes y desde ahí recupera algunos momentos de esa experiencia y realiza algunas proyecciones.

La enunciación está a cargo de Aurora Rojas, una trabajadora ambulante que carga sobre sí (lleva incrustados en su cerebro) a sus cuatro hijos nonatos. Este personaje se halla duplicado: cuenta con una tocaya con la que comparte la marcha, se acompañan, discuten y disienten a lo largo del texto. El cuerpo de la narradora, asimismo, se presenta como materialidad física capaz de resistir al dolor y el agotamiento de la lucha y como territorio de operaciones para sus nonatos que debaten ideas políticas, interpelan a su madre, son cautivados por las pantallas de sus celulares y exhuman los archivos que resguarda ese cerebro ${ }^{8}$.

A lo largo de la lectura llama especialmente la atención que tanto el discurso de la narradora como el de su tocaya operan a través de una digresión permanente que tiende a expandir histórica y geográficamente las referencias socioculturales: la erupción del volcán Bromo en Indonesia, una reunión de líderes del Asia Menor que discuten un acuerdo para la explotación de los recursos naturales del planeta, el comercio del tabaco por parte de la Dinastía Qing, el incendio de la Biblioteca de Alejandría y las celdas de la cárcel de Guantánamo, entre otros. A la manera de una red de hipervínculos, el relato enhebra una serie de imágenes de tragedias humanas. La narradora y su tocaya se presentan como las guardianas de la memoria social del desastre.

Por otra parte, es importante destacar que la narradora se sitúa a lo largo de la novela en una frontera difusa entre sueño y realidad. Incluso ella misma llega a afirmar que se convierte en "una frenética máquina de sueños que parecían contener un futuro que yo nunca podría contener" (Eltit, Sumar 14). Desde mi punto de vista, la práctica de la narración asume un registro convulsionado por la continuidad de las

$8 \quad$ Mónica Barrientos destaca que, a diferencia de lo que sucede en novelas como $E l$ cuarto mundo o Impuesto a la carne, la relación madre-hijo en Sumar manifiesta una agencia divergente: "La madre es parte de este acontecimiento de suma a otros como ella, pero los nonatos tienen su propia agenda, porque son hijos neuronales, producto de la tecnología humana" (160). 
imágenes del pasado y del registro onírico como una pesadilla permanente que, en palabras de la tocaya, agitan la memoria.

El espacio del sueño se presenta como una instancia de interpenetración de imágenes no resueltas, no decodificadas del todo, como una fantasmagoría o un ejercicio de exhumación de archivos y de cuerpos que vagan por las grietas de una memoria inconclusa. En este sentido, resulta especialmente relevante la comparación que realiza la narradora respecto de su actividad dicente:

[...] estoy convencida de que estoy habitada por voces ajenas. Pienso que soy la víctima de una tiránica forma de regresión síquica realizada por Eusapia Palladino, nacida en Bari, Italia, la médium más iluminada del siglo XIX, que quiso traducir al barese los lamentos de un conjunto de muertos. Fantasmas irritados ante la limitación que contenían sus mensajes, porque ellos solo hablaban la lengua de Oc. (Eltit, Sumar 60)

$\mathrm{Al}$ igual que sucede con otras narraciones de Eltit, es posible identificar una relación metafórica que conecta el cuerpo de la narradora con el cuerpo de la escritura/narración (Morales, El discurso crítico... 10) entendidos como territorios polifónicos atravesados por la urgencia de revisitar las huellas de la memoria, de conectar las experiencias individuales con las tragedias del pasado y cepillar a contrapelo el discurso del presente. Como afirma la tocaya: "El tiempo está disuelto y circula en mi interior" (Eltit, Sumar 14). En este sentido, este cuerpo multiforme modula una voz, una máquina de soñar, que es también una máquina de recordar, de narrar y de sobrevivir.

\section{Los hijos del genocidio industrial}

Como señalé anteriormente, en Sumar se relata la gran marcha de los excluidos del sistema, de los ambulantes que han experimentado el hambre y la marginación hasta el extremo: "Hastiados de los golpes que nos propinan las oleadas de desconsideración y desprecio" (Eltit, Sumar 18).

Precisamente, la figura de la marcha se inscribe dentro de una memoria social de luchas y reivindicaciones ciudadanas; una herramienta de intervención social para señalar el desacuerdo con políticas gubernamentales, una modalidad de adquirir visibilidad y defender derechos. 
Dentro de este amplio repertorio de significaciones es posible incluir, por ejemplo, las últimas palabras de Salvador Allende en las que afirmaba que más temprano que tarde se abrirán las grandes alamedas de la historia para que pase el hombre libre. Tomar las calles y llegar a La Moneda se significan en la novela como un anacronismo, un último resto de esperanza ciudadana frente a un escenario social gobernado por el desamparo y la indiferencia: "Somos sombríos. Semihumanos o subhumanos. Un tipo progresivo de zombis pobres que conservan ciertas esperanzas en la poca carne que nos resta" (Eltit, Sumar 84). La marcha, como escenario móvil, configura una forma de subjetividad alternativa que disputa un espacio de representación y de derecho en los diseños de la ciudad neoliberal. En palabras de Mónica Barrientos:

La ocupación de los espacios forma un tipo de marginalidad que no es estática, sino movible, ya que el espacio que utilizan se transforma junto con ellos para configurar una subjetividad que contiene una pulsión comunitaria en que los personajes se asocian y disocian para fisurar los espacios que intentan normalizarlos. (6)

Los ambulantes son los herederos de la Dictadura, "[...] los hijos del genocidio industrial" (Eltit, Sumar 29) que portan en sus cuerpos la evidencia de una política del despojo y la vigilancia. El golpe de Estado, en efecto, constituye una brutal interrupción no solo de un proyecto de desarrollo industrial del país, sino también de los derechos laborales y ciudadanos. En este sentido, es importante destacar que la novela recupera, a través de distintas marcas discursivas, una memoria del movimiento obrero chileno.

En primer lugar, el libro presenta a modo de epígrafe una carta de petición ${ }^{9}$ escrita por el padre de Ofelia Rebeca Villarroel, una de las obreras de Sumar Nylon ${ }^{10}$, que fue arrestada y asesinada por las fuerzas

Este texto ha sido extraído del libro Cartas de petición 1973-1989 de Leónidas Morales. De acuerdo con el autor, en estas cartas "el emisor en cada una de ellas le formula siempre al destinatario una petición cuyo origen remite invariablemente al estado de represión permanente que el golpe militar introduce: saber el paradero de un familiar detenido, que se investiguen los términos inaceptables de una muerte, que se deje en libertad a un detenido sin juicio durante largos meses, que se ponga término a una incomunicación prolongada, que se suspenda la prohibición de abandonar un determinado lugar de residencia, etc. Por eso en adelante me referiré a ellas llamándolas cartas de petición $[\ldots . . .]^{\prime \prime}(2)$.

10 Sumar Nylon fue una industria textil intervenida por el gobierno de la Unidad Popular en el período 1971-1973. Se considera una de las "industrias combativas" debido a 
militares en septiembre de 1973. En este gesto no solo se reactualiza el grito de Antígona que implora por la recuperación del cuerpo de un ser amado para su duelo, sino que también invoca el recuerdo de uno de los emblemas del cooperativismo y la organización del movimiento de los trabajadores.

Por otra parte, la marcha es liderada por dos figuras históricas, dos referentes de las luchas obreras de comienzos del siglo XX: Casimiro Barrios $^{11} \mathrm{y}$ Ángela Muñoz Arancibia ${ }^{12}$. El liderazgo de estos personajes se caracteriza por el despliegue de una serie de mecanismos de captación y control de los participantes de la marcha. La narradora y su tocaya, por su parte, instauran la duda y advierten constantemente acerca de la impostura y el anacronismo que se desprende de la palabra de estos dirigentes:

Mientras el Casimiro Barrios exponía las últimas razones que nos involucraban de manera imperativa en la marcha, mi tocaya me susurró que él nos usaba como meros recursos humanos para extender su voluntariosa persistencia en un mismo fracaso. Dijo que él era la representación más poderosa de la falla producida por una repetición. (Eltit, Sumar 19)

El discurso de Casimiro, además, invoca a la figura de Zenón Torrealba Ilabaca ${ }^{13}$ como símbolo de las derrotas producidas por la des-

\footnotetext{
la efervescencia política que se desarrollaba en su interior: comités de producción, vigilancia y bienestar, además de una fuerte presencia de delegados del Partido Comunista, del Partido Socialista, del Movimiento de Izquierda Revolucionaria y del Movimiento de Acción Popular Unitaria. Luego del golpe militar, el ejército intervino la fábrica, detuvo y, más tarde, desapareció a varios de sus trabajadores. En la actualidad, en el predio funciona "[...] un outlet llamado precisamente "La Fábrica" que mantiene ciertos recuerdos de la antigua cooperativa como vestigios de un pasado glorioso entre medio de la oferta de la última moda de segunda selección para el consumo de la gente de los sectores poblacionales" (Barrientos 41).

${ }_{11}$ Casimiro Barrios Fernández es un anarquista español que se estableció en Chile a los catorce años y en 1920, a los treinta años, fue deportado bajo acusaciones de subversión.

12 Militante anarquista de principios del siglo XX. Lideró en Santiago las primeras organizaciones femeninas de tendencia libertaria como la Federación Cosmopolita de Obreras en Resistencia (1903), la Sociedad de Resistencia de Sombrereras (1906) y la Sociedad de Resistencia de Operarias de la Casa Matus (1907) (Guzzo 135).

13 Zenón Torrealba Ilabaca (Curicó 1875- Santiago 1923) fue senador, dirigente sindical y periodista chileno comprometido con la defensa del movimiento obrero y la democracia. Fue asesinado en el Senado a manos de un compañero del Partido Demócrata, Luis Correa Ramírez.
} 
confianza y las divisiones al interior del movimiento, como mártir de la traición y el descontento. El asesinato del senador se presenta, en este discurso, como uno de los acontecimientos fundacionales de una forma de ejercicio de la política atravesada por la violencia y la aniquilación de cualquier tentativa que invoque "derechos para cuerpos sin moneda" (Eltit, Sumar 150).

Por último, la mercancía misma de los vendedores ambulantes se presenta como resto de otro tiempo, como huella de la tragedia social de la dictadura:

El paño del Diki era blanco, limpio y austero, pero la mercadería que vendía no tenía la menor salida porque se limitaba a exhibir los saldos de una liquidación antigua de la fábrica Corradi (el sueño más probo del tiempo fabril), que había quebrado de manera ilegal en la periferia, después de una huelga prolongada que les resultó convenientes a los promotores de la cesantía y a los explotadores de las horas extraordinarias. (Eltit, Sumar 157)

Los cuerpos de los ambulantes, como el conjunto de piezas deformes que vende el Diki, son el resultado de un diseño político que opera por las leyes de un capitalismo descarnado en el que la vida queda reducida a mero resto orgánico. La memoria de las luchas obreras se manifiesta como una irónica constatación de los fracasos del pasado. Pero, a la vez, el recuento de las tragedias y las desigualdades demanda una acción e interpela desde el presente: "Estábamos exhaustos por las consecuencias del presente, agotados por lo irrisorio de nuestras existencias y muy tristes por la infamia que venía y estaba contenida a plenitud en lo único que conocíamos: nuestro pasado" (Eltit, Sumar 168-169). Atendiendo a lo señalado, es posible afirmar que la noción de memoria en la novela se manifiesta como un sentido activo, plural y político que alude a “[...] un proceso de remembranzas selectivas y en pugna, como maneras de darle significado a la experiencia humana y construir la legitimidad desde ella" (Stern 30).

\section{Habitar las grietas}

Como señalé anteriormente, el cuerpo de la narradora evidencia una metamorfosis que deja de lado cualquier argumento referido a la unicidad del sujeto: se halla duplicado en la figura de su tocaya y alberga 
en su cerebro a cuatro hijos que deciden no nacer. Esta incursión multiplicadora del cuerpo se enmarca en un espacio narrativo dominado (o capturado) por la lógica de lo virtual y las nuevas tecnologías.

Existe una nube que se expande agobiada por la omnipotencia de su captura. Parece invisible aunque porta una materialidad abrumadora. Una nube inubicable para nosotros. Está radicada arriba o abajo o entre los intersticios de un subterráneo o en la síntesis proteica de una comida espacial.

La nube es una cifra inmensa (aun en el paroxismo de su parquedad) que se apodera de la suma de nuestros movimientos. Es ávida, provista de una elasticidad envidiable. Un espacio inclusivo que contiene una flota de robots de última generación y el ocaso fílmico de un astronauta. (Eltit, Sumar 11)

Precisamente, la mirada de la narradora en las primeras páginas de la novela que se inicia en la cúspide - que representan la nube y los satélites como formas de vigilancia y almacenamiento de cada uno de los movimientos de las personas-, luego atiende a los edificios de la ciudad y, finalmente, se focaliza en las veredas donde habitan los ambulantes (Barrientos 39). Este gesto discursivo contribuye a la configuración de una subjetividad ciudadana atravesada (y sujetada) por las tecnologías de la vigilancia.

Asimismo, es posible señalar que la materialidad histórica de los personajes de la novela se disuelve en el escenario de la nebulosa digital:

La Ángela dice que no tenemos que preocuparnos porque somos cuerpos de colección, un abigarrado paquete de antigüedades, dice, y asegura que la nube nos retiene y nos archiva como un derruido recuerdo. Sí, dice, archivados para certificar el fracaso más recurrente de las marchas. Afirma que nos seleccionaron debido a nuestro espíritu añejo. Lo hicieron como testimonio innegable de que estamos completamente discontinuados y por eso ahora formamos parte del catálogo que consigna las secciones clasificadas como archivos del fracaso. Se trata de atesorar experiencias demasiado gastadas por la repetición de decisiones primitivas, y que van a formar parte de los máximos derrotados en este exacto período, el siglo XXI, una época inicial que, según la Ángela, va a ser tan prolongada como la Alta Edad Media. (Eltit, Sumar 115-116) 
En este contexto, la novela elabora una singular constelación metafórica de la memoria en la que se intersectan prácticas y discursos vinculados con el recuerdo de las tragedias del pasado y las prácticas de almacenamiento y conservación de datos en las nuevas ordenaciones electrónicas. Dentro de esta configuración cronotópica ${ }^{14}$, se anula la linealidad del tiempo y todas las referencias históricas conviven en un presente que actualiza a cada momento su repertorio trágico: “[...] aunque sorteamos el permanente bombardeo a la moneda, no logramos evadirla" (Eltit, Sumar 170).

La imagen-recuerdo del Palacio de La Moneda en llamas, deshaciéndose, se reitera a lo largo de la novela como una metáfora múltiple que alude a la interrupción del orden de un proyecto democrático alternativo y también a la desmaterialización (Guerrero s/p) y sumisión de las narrativas nacionalistas a las lógicas del capital. Esta imagen inaugura un tiempo nuevo

[...] realista, pragmático, tanto que ya había emprendido el proceso de destrucción de todas las vidas que no resultaran proclives a resignarse o a inclinarse ante la moneda o a llorar, a implorar y revolcarse frente a la imposibilidad de contar con una montaña de monedas. (Eltit, Sumar 102-103)

Por otra parte, es importante destacar que las referencias a la carta de petición que antecede al texto gravitan a lo largo de la novela como parte de un archivo mental del terror. Los nonatos, que marchan colgados de una "memoria umbilical" (57), custodian un archivo de imágenes, documentos, cartas y diversos escombros que se reciclan infinitamente en la mente de su madre. En este sentido, se revelan como archiveros y hermeneutas de una historia que resiste (Ramos s/p): "A la esperanza en esa ceremonia se plegaron mis hijos, porque estimaron que la carta debía ser leída justo afuera de la moneda, en el centro de su reconstrucción, después de los hoyos considerables causados por las bombas" (Eltit, Sumar 107).

La desclasificación y lectura coral de la carta funda un acto de rebeldía que pretende escalar el revés de la historia e insistir en la ac-

14 Recupero la noción bajtiniana de cronotopo novelesco para referir “[...] la conexión esencial de las relaciones temporales y espaciales asimiladas artísticamente en la literatura" (Bajtín 237). 
tualidad de la tragedia. Así, en un mundo condenado a la repetición y capturado por las nubes electrónicas, la figura de estos nonatos no solo condensa una serie de metáforas que aluden a la responsabilidad política de transmisión y conservación de las memorias colectivas, sino que también inaugura una grieta para repensar el proyecto humano.

\section{Consideraciones finales}

La noción de memoria gravita a lo largo de toda la producción literaria de Diamela Eltit como una preocupación estética y política que podría resumirse a través de la siguiente interrogante: ¿cómo habitar políticamente los signos literarios y, a la vez, eludir las mallas del realismo y las estéticas del significado único? (Richard, Feminismo 90). En el caso específico de Sumar esta pregunta se traduce en un particular enlace de metáforas que fundamentan una lectura dialéctica de la relación pasado-presente.

La representación de los marchantes como hijos del genocidio industrial y el amplio repertorio de referencias a las luchas del movimiento obrero, activa una estrategia de lectura que atiende a las relaciones entre este discurso novelístico con la experiencia histórica de la violencia política y económica instaurada por la dictadura militar en 1973. La retórica de la novela, como he señalado anteriormente, lejos de asimilar un modelo lineal del tiempo histórico, se organiza en torno a la permanencia de las tragedias. Parafraseando al ensayo de la autora, la representación del escenario social chileno contemporáneo permanece atrapado entre las llamas del Palacio de La Moneda (Eltit, "Sociedad anónima" 29).

Asimismo, el cuerpo de la narradora se representa como un territorio en el que se inscriben las huellas del tiempo. Aurora Rojas transita diversos estadios como ambulante que marcha para alcanzar la moneda, como espacio de la gestación de sus nonatos, como máquina de contar/soñar historias y como archivo que resguarda las claves para entender el presente.

Por último, la omnipresencia de la nube que contiene, vigila y archiva la vida en la comunidad de los ambulantes esboza una crítica a la incesante penetración de las redes virtuales y del modo en que inter- 
vienen en la organización y percepción de las experiencias humanas (Scarabelli 201). En este sentido, frente a un horizonte social y político gobernado por la repetición y la estandarización de los signos, la novela instaura una ruptura que reivindica la potencia comunicativa de la ambigüedad, la polifonía y el desplazamiento del significante como estrategias de reactivación y recuperación de la memoria.

\section{Referencias bibliográficas}

Ansaldi, Waldo y Verónica Giordano. América Latina: La construcción del orden (Tomo II). Buenos Aires, Ariel, 2012.

Avelar, Idelber. Alegorías de la derrota: la ficción posdictatorial y el trabajo del duelo. Santiago de Chile, Escuela de Filosofía de la Universidad ARCIS, 2008.

Bajtín, Mijaíl. Teoría y estética de la novela. Madrid, Taurus, 1989.

Benjamin, Walter. Conceptos de filosofía de la historia. La Plata, Terramar, 2007.

Barrientos, Mónica. La pulsión comunitaria en la obra de Diamela Eltit. Pittsburgh, Latin American Research Commons, 2019.

Brito, Eugenia. Campos minados (Literatura post-golpe en Chile). Santiago de Chile, Editorial Cuarto Propio, 1990.

Brunner, José Joaquín. “Cultura y sociedad en transición”. Debates críticos en América Latina. 36 números de la Revista de Crítica Cultural (1990-2008). Coord. Nelly Richard. Santiago de Chile, ARCIS/Editorial Cuarto Propio, 2008, pp. 49-59.

Cabrera, Mario Federico David. El archivo y las modulaciones de la memoria en la escritura de Pedro Lemebel. A contracorriente. Una revista de estudios latinoamericanos, vol. 17, no. 1, 2019, pp. 65- 85.

Cánovas, Rodrigo. "Diamela Eltit. Algunos años antes, algunos años después". Diamela Eltit: redes locales, redes globales. Ed. Rubí Carreño Bolívar. Madrid, Iberoamericana Vervuert, 2009, pp. 25-32.

Carreño Bolívar, Rubí. Leche amarga: violencia y erotismo en la narrativa chilena del siglo XX (Bombal, Brunet, Donoso, Eltit). Santiago de Chile, Editorial Cuarto Propio, 2007.

Corbin, Megan. "Archiveras anarquistas: Corporal Testimony in the Work of Diamela Eltit". Catedral tomada: Revista de Crítica Literaria Latinoamericana, vol. 1, no. 1, 2013, pp. 1-17. 
Dorfman, Ariel. Más allá del miedo: el largo adiós a Pinochet. Madrid, Siglo XXI editores, 2002.

Eltit, Diamela. Sumar. Santiago de Chile, Seix Barral, 2018.

Eltit, Diamela. Lumpérica. Santiago de Chile, Seix Barral, 2008.

Eltit, Diamela. “Sociedad anónima”. Emergencias. Escritos sobre literatura, arte y política. Santiago de Chile, Planeta, 2000, pp. 28-40.

Faletto, Enzo. “De la teoría de la dependencia al proyecto neoliberal: el caso chileno". Antología del pensamiento crítico chileno contemporáneo. Comps. Leopoldo Navarro Benavidez, Milton Godoy Orellana y Francisco Vergara Edwards. Buenos Aires, CLACSO, 2015, pp. 57-77.

Guerrero, Javier. “Las nubes de Diamela Eltit”. Revista Transas. Letras y Artes de América Latina, 2018. Recuperado de https://www. revistatransas.com/2018/09/14/las-nubes-de-diamela-eltit/

Guzzo, Cristina. Libertarias en América del Sur. De la A a la Z. Buenos Aires, Libros de Anarres, 2014.

Halwachs, Maurice. La mémoire collective. Paris, Puf, 1950.

Morales, Leónidas. "El discurso crítico de Diamela Eltit: cuerpo y política". Emergencias. Escritos sobre literatura, arte y política. Diamela Eltit. Santiago de Chile, Ariel, 2000, pp. 9-16.

Morales, Leónidas. Cartas de petición. Cyber Humanitatis, n 9, 1999, pp. 1-6.

Ramos, Julio. "Sumar de Diamela Eltit, el excedente radical de la ficción”. Mimesis, 2019. Recuperado de https://edicionesmimesis.cl/index.php/2019/04/10/sumar-de-diamela-eltit-elexcedente-radical-de-la-ficcion-por-julio-ramos/

Richard, Nelly. La insubordinación de los signos (cambio politico, transformaciones culturales y poéticas de la crisis). Santiago de Chile, Editorial Cuarto Propio, 1994.

Richard, Nelly. “Tres funciones de la escritura: deconstrucción, simulación, hibridación”. Una poética de literatura menor: la narrativa de Diamela Eltit. Ed. Juan Carlos Lértora. Santiago de Chile, Editorial Cuarto Propio, 1993, pp. 37-51.

Richard, Nelly. Latencias y sobresaltos de la memoria inconclusa (Chile: 1990- 2015). Córdoba, Eduvim, 2017.

Richard, Nelly. Feminismo, género y diferencia(s). Santiago de Chile, Palinodia, 2018. 
Rotger, Patricia. Memoria sin tiempo: prácticas narrativas de la memoria en escritoras argentinas de la posdictadura. Córdoba, Comunicarte, 2014.

Scarabelli, Laura. Escenarios del nuevo milenio. La narrativa de Diamela Eltit (1998- 2018). Santiago de Chile, Editorial Cuarto Propio, 2014.

Stern, Steve. Recordando el Chile de Pinochet. En vísperas de Londres 1998. Santiago de Chile, Ediciones Universidad Diego Portales, 2009. 